\title{
Synthesis, Structural Characterization and Hydrogen Bonding of Mono(salicylidene)carbohydrazide
}

\author{
Predrag Novak,,${ }^{\text {a,* }}$ Tomislav Jednačak, ${ }^{\text {a Jelena Parlov Vuković, }{ }^{\text {b }} \text { Klaus Zangger, }}{ }^{\mathrm{c}}$ \\ Mirta Rubčić, ${ }^{\mathrm{a}}$ Nives Galić, ${ }^{\mathrm{a}}$ and Tomica Hrenar ${ }^{\mathrm{a}}$ \\ ${ }^{a}$ Department of Chemistry, Faculty of Natural Sciences, University of Zagreb, Horvatovac 102a, HR-10000 Zagreb, Croatia \\ ${ }^{\mathrm{b}}$ INA-Industrija nafte d.d., Refining \& marketing business division, Product development department, Lovinčićeva bb, \\ HR-10002 Zagreb, Croatia \\ ${ }^{\mathrm{c}}$ Institute of Chemistry, Organic and Bioorganic Chemistry, University of Graz, Heinrichstrasse 28, A-8010 Graz, Austria
}

\begin{abstract}
The condensation reaction between carbohydrazide and salicylaldehyde in different solvents gave mono(salicylidene)carbohydrazide (1). The structure of $\mathbf{1}$ in solution has been determined by using experimental (NMR and UV spectroscopies and Mass spectrometry) and quantum chemical (DFT) methods. It has been demonstrated that $\mathbf{1}$ adopts the hydroxy-one tautomeric form which is in accordance with previously published results for the related systems. Changes in NMR chemical shifts and calculations have pointed towards a formation of intra- and intermolecular hydrogen bonds, the later being weaker and easily broken at higher temperatures. These results can further be exploited for better understanding of the role hydrogen bonds can play in bioactivity of related derivatives. (doi: 10.5562/cca2123)
\end{abstract}

Keywords: mono(salicylidene)carbohydrazide, hydrogen bonding, NMR and UV spectroscopy, mass spectrometry, quantum chemical calculations

\section{INTRODUCTION}

Schiff bases constitute a privileged class of organic compounds, since they can easily be prepared by a condensation of appropriate primary amine and carbonyl compounds. ${ }^{1}$ Although they have been extensively investigated for over a century, they still attract a considerable attention. ${ }^{2,3}$ Schiff bases posses a number of interesting biological properties, ${ }^{4}$ as well as a wide range of analytical and industrial applications. ${ }^{5}$ On the other hand, their ability to bind and stabilize different metal ions in various oxidation states, not only enable their use as reagents in analytical chemistry, but also makes them exquisite compounds for the design of coordination systems with biological activity. ${ }^{6}$

Among a variety of Schiff bases especially interesting are those derived from di- or tri-amines. These can be, by proper choice of carbonyl compounds, easily tailored for construction of multinuclear coordination systems. ${ }^{7}$ The parent amine largely dictates the nature of the final imino product, usually giving equivalently substituted bis- or tris- compounds of the same amino group environment. ${ }^{8}$ However, in rare cases asymmetrically substituted products can be synthesized by a proper synthetic approach. One of the procedures relies on the gradual reaction of the amino and carbonyl groups producing first monosubstituted derivatives, and then gradually higher substituted products. ${ }^{9-11}$

Mono(salicylidene)carbohydrazide (1), i.e. monosubstituted derivative of carbohydrazide is closely related to urea. Several examples of carbohydrazide monosubstituted derivatives have been already described in the literature, but all these reports lack detailed structural characterization. ${ }^{12}$ Since such system offers wide possibilities for the synthesis of asymmetric Schiff bases, we conducted a detailed structural characterization in solution.

Hydrogen bonding is a crucial factor that affects the overall structure and functionality of biologically important molecules. It is also known that hydrogen bonds are key interactions in molecular recognition process and in binding of ligands to receptor. Many of bioactive molecules and drugs exert their biological activity via hydrophobic and/or hydrogen bonding interactions with their biological targets. ${ }^{13,14}$ Hence, it is important to get a closer insight into these interactions in order to design molecules with improved biological profile. Hydrogen bonds in solution are usually studied by the use of various spectroscopic and theoretical

\footnotetext{
$\dagger$ This article belongs to the Special Issue devoted to the $85^{\text {th }}$ anniversary of Croatica Chemica Acta.

* Author to whom correspondence should be addressed. (E-mail: pnovak@chem.pmf.hr)
} 
<smiles>NNC(=O)N/N=C/c1ccccc1O</smiles>

Scheme 1. The structure of 1 and the atom numbering.

methods. Here, we employed one- and two-dimensional NMR techniques, UV spectroscopy, MS spectrometry and quantum chemical calculations to study structure and hydrogen bonding in solution of $\mathbf{1}$. This compound has several reactive groups which can participate in both intra- and intermolecular hydrogen bonding (Scheme 1). It can exist in several tautomeric forms as depicted in Figure 1. Our previous studies on the related systems revealed that different media (solvents) and temperature may influence the nature and structure of hydrogen bonds. ${ }^{15-18}$ Hence, these experiments were aimed to explore the influence of solvents of different polarities and temperature on the strength and structure of hydrogen bonding and tautomeric equilibria in $\mathbf{1}$.

\section{EXPERIMENTAL}

\section{Materials}

Carbohydrazide, salicylaldehyde, methanol, DMSO- $\mathrm{d}_{6}$ and DMF- $\mathrm{d}_{7}$ were purchased from commercial sources and used without further purification.

\section{Synthesis of mono(salicylidene)carbohydrazide}

Carbohydrazide $(0.20 \mathrm{~g} ; 2.22 \mathrm{mmol})$ was stirred and heated in $15 \mathrm{~cm}^{3}$ of methanol until complete dissolution. Afterwards, salicylaldehyde (0.27 g; $2.22 \mathrm{mmol})$ was added to a carbohydrazide solution and the reaction mixture was stirred and heated for additional 2 hours. During heating, white needle-like product started to deposit. The product was filtered, washed with cold methanol $\left(5 \mathrm{~cm}^{3}\right)$ and dried under vacuo. Yield: $0.32 \mathrm{~g}(74 \%)$.

\section{NMR Spectroscopy}

NMR spectra were recorded on Bruker Avance 300 and 500 spectrometers from samples in $5 \mathrm{~mm}$ NMR tubes at 298 K. DMSO-d $\mathrm{d}_{6}$ and DMF-d $\mathrm{d}_{7}$ were used as solvents and TMS as internal standard. Sample concentration was $1.2 \times 10^{-2} \mathrm{~mol} \mathrm{dm}^{-3}$. Concentration dependent meas- urements were performed in the range $2 \times 10^{-1}$ to $6 \times 10^{-3}$ mol dm$~^{-3}$. Temperature dependent experiments were conducted in the range 30 to $90{ }^{\circ} \mathrm{C}$ in DMSO- $\mathrm{d}_{6}$.

Proton spectra with spectral width of $6200 \mathrm{~Hz}$ and a digital resolution of $0.09 \mathrm{~Hz}$ per point were measured with 16 scans.

${ }^{13} \mathrm{C}$ proton decoupled, DEPT 90 and DEPT 135 spectra with spectral widths of $18030 \mathrm{~Hz}$ were collected with 256 to 1024 scans. Digital resolution was $0.11 \mathrm{~Hz}$ per point for ${ }^{13} \mathrm{C}$ proton decoupled experiment and 0.55 $\mathrm{Hz}$ per point for DEPT experiments.

In the gCOSY experiment 2046 points in the $f 2$ dimension and 256 increments in the $f 1$ dimension were used. For each increment 4 scans and the spectral width of $3086 \mathrm{~Hz}$ were applied. Digital resolution was 3.03 and $24.39 \mathrm{~Hz}$ per point in $f 2$ and $f 1$ dimensions, respectively. Typical spectral conditions for gHSQC and gHMBC spectra were as follows. Spectral width was $2994 \mathrm{~Hz}$ in $f 2$ and $16605 \mathrm{~Hz}$ in $f 1$ dimension for both experiments. $2 \mathrm{~K}$ data points were applied in the time domains and for each data set 256 and 128 increments were collected for gHSQC and gHMBC spectra, respectively. The resulting digital resolution was $2.94 \mathrm{~Hz}$ per point in $f 2$ dimension and 125.1 and $250.0 \mathrm{~Hz}$ per point in $f 1$ dimension in gHSQC and gHMBC spectra, respectively.

Phase-sensitive TPPI NOESY spectra were recorded under the following conditions: spectral width was $7003 \mathrm{~Hz}$ in both dimensions, 4K data points were applied in time domain and 256 increments were collected for each data set with linear prediction to $2 \mathrm{~K}$ and zero filling to $4 \mathrm{~K} .32$ scans were applied for each increment. A relaxation delay was $1.5 \mathrm{~s}$. The spectra were obtained with the mixing time of $500 \mathrm{~ms}$ and processed with sine squared function shifted by $\pi / 2$ in both domains.

\section{MS Spectrometry}

The ESI mass spectrum was obtained on Agilent 6420 Triple Quadrupole Mass Spectrometer (Agilent Technologies, Palo Alto, CA, USA). Mass spectrum was recorded in the range of $m / z=100$ to $\mathrm{m} / z=1500$ in positive ion mode. The sample was introduced in mass spectrometer directly via Agilent 1200 HPLC system. Capillary potential was $4 \mathrm{kV}$, and fragmentor voltage $135 \mathrm{~V}$. Gas temperature was $350^{\circ} \mathrm{C}$, and gas flow rate $12 \mathrm{dm}^{3} / \mathrm{min}$. Tandem mass spectrometry was performed with collision energy of $10 \mathrm{eV}$.<smiles>NN=C(O)N/N=C/c1ccccc1O</smiles>

Figure 1. Tautomeric forms of $\mathbf{1 .}$ 
Solution of 1 for acquiring MS spectra was prepared by dissolving $1 \mathrm{mg}$ of solid in $0.1 \mathrm{~cm}^{3}$ of DMSO, and adding $0.9 \mathrm{~cm}^{3}$ of methanol.

\section{UV Spectroscopy}

UV-Vis spectra in the spectral range from 250 to 500 $\mathrm{nm}$ were acquired by means of a Varian Cary $3 \mathrm{spec}-$ trometer using conventional quartz cells $(10 \times 10 \mathrm{~mm})$.

Stock solution of $\mathbf{1}$ was prepared by dissolving weighted solid in DMSO. The working solutions were prepared in $10.0 \mathrm{~cm}^{3}$ flask by adding stock solution, appropriate amount of water and DMSO, resulting in the mixed solvents of the volume ratios $V(\mathrm{DMSO}) /$ $V\left(\mathrm{H}_{2} \mathrm{O}\right)=9 / 1$ to $1 / 9$.

\section{Quantum Chemical Calculations}

All quantum chemical calculations were performed using the Gaussian 09 program package. ${ }^{19}$ Geometry optimization for ground and transition states were performed at the B3LYP/6 311++G(d,p) level of the theory. ${ }^{20,21}$ In order to increase numerical accuracy, verytight optimization convergence criteria was used while twoelectron integrals and their derivatives were calculated by using the pruned integration grid having 99590 points. For all optimized structures harmonic frequencies were calculated to insure that obtained geometries correspond to the local minimum (or maximum) on the potential energy surface. Solvation effects were incorporated in the calculations using the reformulation of polarizable continuum model (PCM) ${ }^{22,23}$ known as integral equation formalism (IEFPCM) of Tomasi and coworkers. ${ }^{24-27}$ The standard Gibbs energies of binding was calculated at $T=298.15 \mathrm{~K}$ and $p=101325 \mathrm{~Pa}$ by subtraction of Gibbs energies for separate molecules from the Gibbs energy of complex. Isotropic shieldings in vacuo and in solvent were calculated by applying the gauge-independent atomic orbital (GIAO) and PCM GIAO ${ }^{28,29}$ methods on the previously optimized geometries using the same basis set as that above. Chemical shifts were calculated with respect to tetramethylsilane (TMS).

\section{RESULTS AND DISCUSSION}

\section{Synthesis}

The condensation reaction in methanol between carbohydrazide and salicylaldehyde in 1:1 molar ratio afforded mono(salicylidene)carbohydrazide.

\section{NMR Assignments and Structure Elucidation}

Proton and carbon chemical shifts were assigned by a combined use of one- $\left({ }^{1} \mathrm{H}\right.$, APT or ${ }^{13} \mathrm{C}$ proton decoupled) and two-dimensional NMR experiments (COSY, HSQC and HMBC). In order to assess conformation of
Table 1. ${ }^{1} \mathrm{H}$ and ${ }^{13} \mathrm{C}$ NMR chemical shifts for $\mathbf{1}$ in DMSO- $\mathrm{d}_{6}$ and $\mathrm{DMF}-\mathrm{d}_{7}$ at ambient temperature

\begin{tabular}{lcccccc}
\hline \multirow{2}{*}{ Atom } & \multicolumn{2}{c}{$\delta / \mathrm{ppm}(\mathrm{DMSO})$} & & \multicolumn{2}{c}{$\delta / \mathrm{ppm}(\mathrm{DMF})$} \\
\cline { 2 - 3 } \cline { 6 - 7 } & ${ }^{1} \mathrm{H}$ & ${ }^{13} \mathrm{C}$ & ${ }^{13} \mathrm{C}^{(\mathrm{a})}$ & & ${ }^{1} \mathrm{H}$ & ${ }^{13} \mathrm{C}$ \\
\hline$\alpha$ & 8.20 & 140.05 & 151.37 & & 8.46 & - \\
$1^{\prime}$ & 10.40 & & & & 10.99 & \\
$2^{\prime}$ & & 157.30 & 162.55 & & 157.24 \\
$3^{\prime}$ & 7.90 & & & 8.05 & \\
$4^{\prime}$ & 4.12 & & & & 4.32 & \\
1 & & 120.49 & 125.70 & & 120.01 \\
2 & & 156.60 & 168.14 & & 157.00 \\
3 & 6.84 & 116.46 & 122.97 & & 6.95 & 116.25 \\
4 & 7.18 & 130.61 & 138.54 & & 7.25 & 130.27 \\
5 & 6.81 & 119.62 & 125.73 & & 6.90 & 119.22 \\
6 & 7.66 & 128.12 & 138.25 & & 7.61 & 128.68 \\
OH & 10.40 & & & & 10.53 & \\
\hline
\end{tabular}

(a) Calculated GIAO ${ }^{13} \mathrm{C}$ chemical shifts (with respect to TMS) at the B3LYP/6-311++G(d,p) level of theory.

$\mathbf{1}$ in solution two-dimensional NOESY sequence was applied. Owing to a very low solubility of $\mathbf{1}$ in most of NMR solvents, the spectra were recorded only in DMSO- $\mathrm{d}_{6}$ and DMF- $\mathrm{d}_{7}$ solutions. The chemical shifts in two solvents are very similar and are given in Table 1. Calculated GIAO ${ }^{13} \mathrm{C}$ chemical shift shows a good agreement with the experimental values confirming our initial assignments. Systematic differences in calculated shifts emerge due to a balance between the accuracy determined by the method used and computational costs.

As already mentioned, 1 might exist in several tautomeric forms shown in Figure 1. Additionally, the keto-tautomer in the benzene ring is also possible but it was excluded on the basis of proton and carbon chemical shift values. The molecule can also adopt cis- or trans-configuration around the $\mathrm{C}=\mathrm{N}$ double bond. The trans-isomer is stabilized by an intramolecular $\mathrm{OH} \cdots \mathrm{N}$ hydrogen bond. On the basis of NMR spectral analysis no trace of $c i s$-isomer was found.

The presence of COSY correlation peak between $\mathrm{NH} 2$ protons and neighboring NH3' proton and NOESY cross peak between $\mathrm{CH} \alpha$ and $\mathrm{NH}^{\prime}$ indicate that the dominant form in both solvents is tautomeric form 1a.

Signals of all $\mathrm{OH}$ and $\mathrm{NH}$ protons are significantly broadened indicating the presence of hydrogen bonding and chemical exchange. The large up-field shift of $\mathrm{OH}$ over 10 ppm reflects strong $\mathrm{OH} \cdots \mathrm{N}$ intramolecular hydrogen bond (Figure 1).

NMR chemical shifts of $\mathrm{OH}$ and NH1' protons show only very small changes with different solution concentrations, as previously reported for related systems, ${ }^{12,14}$ corroborating that intramolecular hydrogen bonds dominate here. 


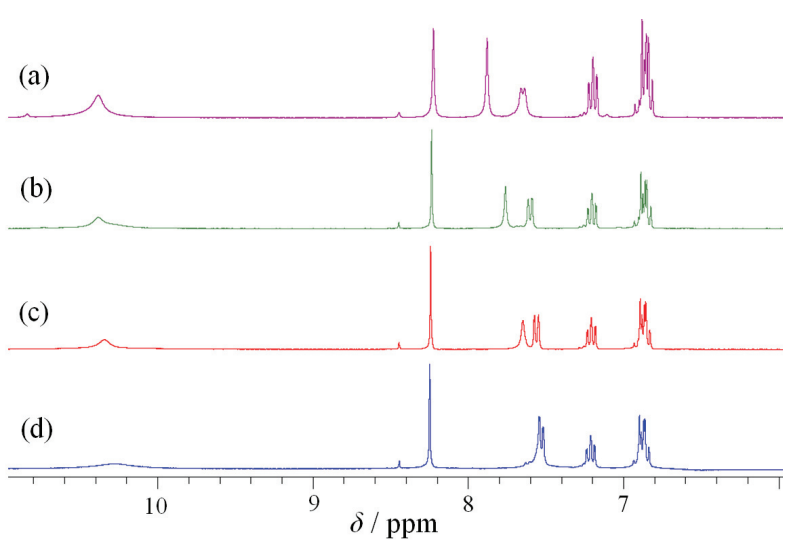

Figure 2. ${ }^{1} \mathrm{H}$ NMR spectra of 1 in DMSO- $\mathrm{d}_{6}$ at (a) $30{ }^{\circ} \mathrm{C}$, (b) $50{ }^{\circ} \mathrm{C}$, (c) $70{ }^{\circ} \mathrm{C}$ and (d) $90^{\circ} \mathrm{C}$.

On the other hand, raising the temperature up to $90{ }^{\circ} \mathrm{C}$ in DMSO had the largest effect on NH3' protons $(0.336 \mathrm{ppm})$ and smaller effect on $\mathrm{OH}$ and $\mathrm{NH} 1^{\prime}(0.123$ ppm). Both effects are shielding e.g. shifts to lower ppm values were observed at higher temperatures (Figure 2). The larger shift of NH3' proton is in accordance with the fact that this group form weaker intermolecular hydrogen bonds with solvent molecules which are more easily broken at higher temperatures.

Hence NMR data showed that $\mathbf{1}$ primarily exists as hydroxy-one tautomeric form $\mathbf{1 a}$ in solution which is stabilized by a strong intramolecular $\mathrm{OH} \cdots \mathrm{N}$ hydrogen bond. Intermolecular interactions with solvent are also present being in accordance with previously published results. $^{15-17}$

\section{MS and UV Analysis}

In MS spectrum of $\mathbf{1}\left(\mathrm{C}_{8} \mathrm{H}_{10} \mathrm{~N}_{4} \mathrm{O}_{2}\right.$, exact mass is 194.08) the base signal at $m / z=195.1$ was assigned to protonated molecular ion, $[\mathrm{M}+\mathrm{H}]^{+}$. The signal of sodium adduct, $[\mathrm{M}+\mathrm{Na}]^{+}$appeared at $m / z=217.1$, while signals of fragment ions were at lower $\mathrm{m} / \mathrm{z}$ values $(120.1 ; 122.2$;

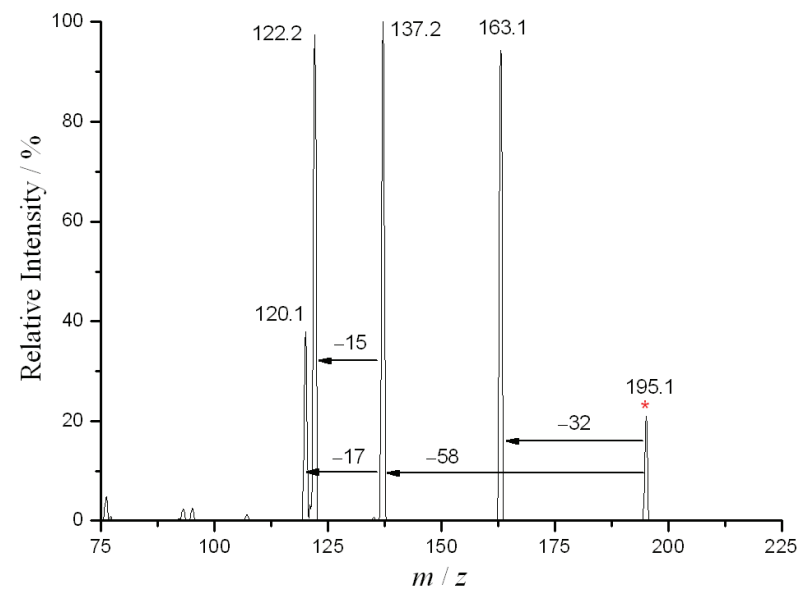

Figure 3. MS/MS spectrum of $\mathbf{1}(\mathrm{m} / \mathrm{z}=195.1)$ at $10 \mathrm{eV}$.

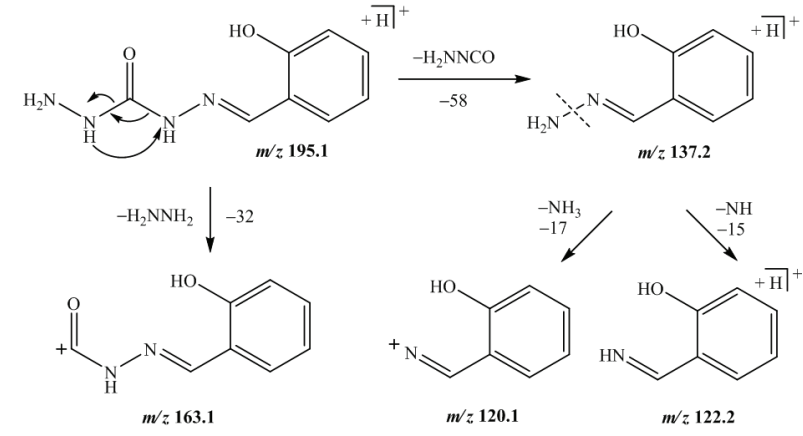

Scheme 2. Proposed fragmentation pathway of protonated molecular ion $[\mathbf{1}+\mathrm{H}]^{+}(m / z=195.1)$ at $10 \mathrm{eV}$.

137.2 and 163.1). The MS/MS spectrum of $\mathbf{1}$ is shown in Figure 3, and the proposed fragmentation in Scheme 2.

The UV-Vis spectra of $\mathbf{1}$ in DMSO and DMF are shown in Table 2 . The band at $\approx 323 \mathrm{~nm}$, which was also observed in the UV spectra of salicylaldehyde, corresponds to the aldehide part of hydrazone. The band at $290 \mathrm{~nm}$ (288 $\mathrm{nm}$ in DMF) can be assigned to azomethine $\mathrm{C}=\mathrm{N}$ bond, ${ }^{30,31}$ while the band in the spectral region 281-283 $\mathrm{nm}$ can be attributed to the hydrazide part of molecule since the broad band with maximum at $277 \mathrm{~nm}\left(\varepsilon=216.5 \mathrm{dm}^{3} \mathrm{~mol}^{-1} \mathrm{~cm}^{-1}\right)$ was observed in DMSO solution of carbohydrazide.

The absorption electronic spectra of 1 were also acquired in the mixtures of DMSO and water. The addition of water into the system caused a decrease in absorbance at higher, and increase in absorbance at lower wavelengths (Figure 4). At the same time, a hypsochromic shift from $323 \mathrm{~nm}$ to $314 \mathrm{~nm}$ and from $283 \mathrm{~nm}$ to $278 \mathrm{~nm}$ occur, indicating a possible $E / Z$ isomerisation of monosubstituted hydrazone. ${ }^{32,33}$ The appearance of a new band in the spectral region around $400 \mathrm{~nm}$, characteristic for ketoamine-enolimine tautomeric interconversion, ${ }^{34,35}$ was not observed. This is in accordance with NMR data.

\section{Quantum Chemical Calculations}

Optimized structures 1a-1c are presented in Figure 5 and relative standard Gibbs energies are given in Table 3.

As already indicated by NMR, the most stable form of $\mathbf{1}$ in vacuo and in solution is hydroxy-one

Table 2. UV-Vis absorption spectra of $\mathbf{1 .}$

\begin{tabular}{cc}
\hline Solvent & $\lambda / \mathrm{nm}\left(10^{-4} \varepsilon / \mathrm{dm}^{3} \mathrm{~mol}^{-1} \mathrm{~cm}^{-1}\right)$ \\
\hline \multirow{3}{*}{ DMSO } & $323(1.2996)$ \\
& $290(1.3389)$ \\
& $283(1.3682)$ \\
& $320(1.2553)$ \\
DMF & $288(1.5565)$ \\
& $281(1.5986)$ \\
\hline
\end{tabular}




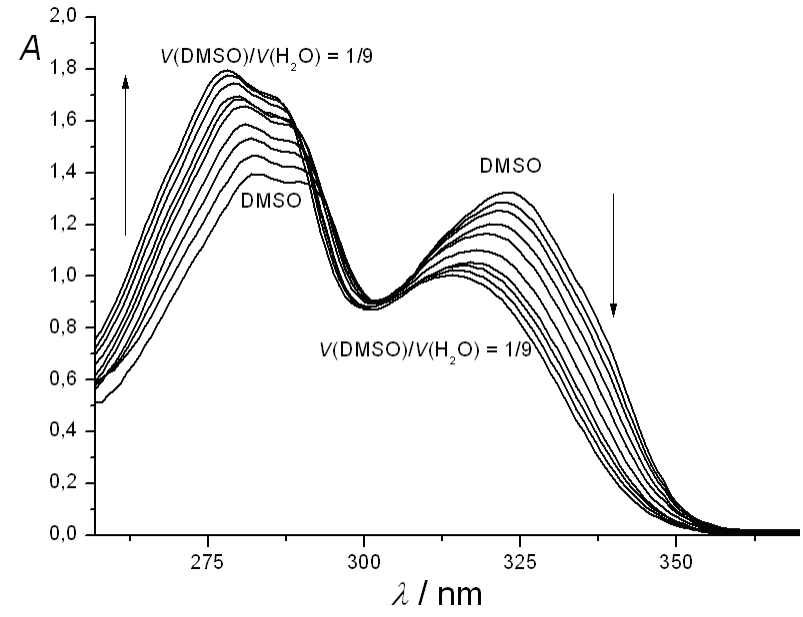

Figure 4. UV-Vis spectra of $\mathbf{1}$ in DMSO and DMSO/ $\mathrm{H}_{2} \mathrm{O}$ mixtures: $V(\mathrm{DMSO}) / V\left(\mathrm{H}_{2} \mathrm{O}\right),=9 / 1,8 / 2,7 / 3,6 / 4,5 / 5,4 / 6,3 / 7$, $2 / 8$, and $1 / 9 . c(\mathbf{1})=1 \times 10^{-4} \mathrm{~mol} \mathrm{dm}^{-3}$. Arrows show the change in absorbance with the increase in water content in DMSO/ $\mathrm{H}_{2} \mathrm{O}$ mixtures.

form. ${ }^{15}$ Relative differences in Gibbs energy for $\mathbf{1 b}$ and 1c forms in vacuo are 36.45 and $62.25 \mathrm{~kJ} \mathrm{~mol}^{-1}$ respectively, while calculations incorporating the solvent effects of DMSO within the IEFPCM model gave the differences of 56.56 and $76.31 \mathrm{~kJ} \mathrm{~mol}^{-1}$, respectively. These values confirmed that the most dominant form in solution is 1a.
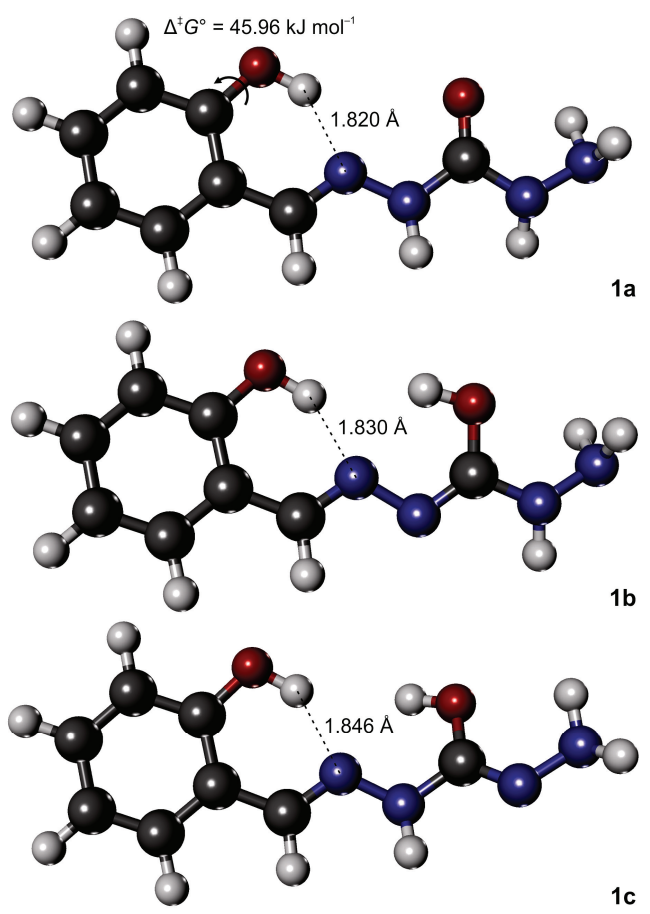

Figure 5. Optimized structures of 1a-1c (B3LYP/6 $311++g(d, p)$ level of the theory, solvent effects of DMSO were incorporated using the IEFPCM method, barrier for rotation of hydroxyl group in $\mathbf{1 a}$ is given).
Table 3. Calculated standard Gibbs energies at $298.15 \mathrm{~K}$ and $101325 \mathrm{~Pa}$ for 1a-1c (relative to 1a, B3LYP/6 311++g(d,p) level of the theory, solvent effects were incorporated using the IEFPCM method)

\begin{tabular}{lcc}
\hline \multirow{2}{*}{ Molecule } & \multicolumn{2}{c}{$\Delta_{\mathrm{r}} G^{\circ} / \mathrm{kJ} \mathrm{mol}^{-1}$} \\
\cline { 2 - 3 } 1a & in vacuo & DMSO $\left(\varepsilon_{\mathrm{r}}=46.826\right)$ \\
1b & 0.00 & 0.00 \\
1c & 36.45 & 56.56 \\
\hline
\end{tabular}

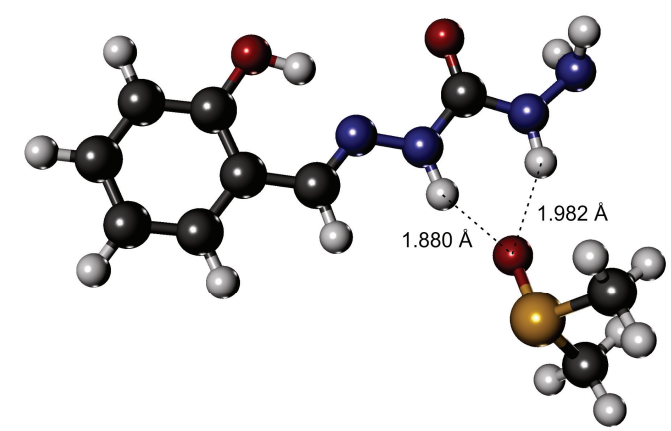

Figure 6. Optimized structures of complex between 1a with one molecule of DMSO (B3LYP/6 311++g(d,p) level of the theory, solvent effects of DMSO were incorporated using the IEFPCM method).

Strength of the intramolecular hydrogen bond in $1 \mathrm{a}$ is $42.62 \mathrm{~kJ} \mathrm{~mol}^{-1}$ calculated in vacuo and $28.99 \mathrm{~kJ}$ $\mathrm{mol}^{-1}$ in DMSO and can be categorized as moderate. ${ }^{36}$ Standard Gibbs energy of activation for the rotation of hydroxyl group is almost twice as much as this value (Figure 5). On the other hand, the strength of the threecenter hydrogen bond formed between $\mathrm{NH}$ groups and a DMSO molecule (Figure 6) is calculated to be $11.21 \mathrm{~kJ}$ $\mathrm{mol}^{-1}$ in vacuo. This supports our experimental findings based on NMR measurements that the intermolecular hydrogen bonds with solvent molecules are much weaker than the intramolecular one and are easier to break at higher temperature.

\section{CONCLUSION}

It has been demonstrated that the mono(salicylidene)carbohydrazide (1) can be prepared in various solvents by the condensation of carbohydrazide and salicylaldehyde in different yields. The structure of $\mathbf{1}$ in solution has been characterized by both intra- and intermolecular hydrogen bonding and the molecule has been found to exist in the localized hydroxy-one tautomeric form. Apart form intramolecular hydrogen bonds experimental evidence and DFT calculations have pointed towards the formation of three-center hydrogen bonds with solvent molecules. Quantum chemical calcu- 
lations supported experimental findings based on NMR measurements that the intermolecular hydrogen bonds with solvent molecules are much weaker than the intramolecular ones and hence easier to break at higher temperature.

Acknowledgements. We thank the Ministry of Science, Education and Sports of the Republic of Croatia (Project No. 1191191342-1083 and 119-1191342-1082) for the financial support.

\section{REFERENCES}

1. S. Patai, Carbon-nitrogen double bonds, Interscience Publishers, John Wiley and Sons, London, 1970.

2. T. T. Tidwell, Angew. Chem. Int. Ed. 47 (2008) 1016-1020.

3. A. Blagus, D. Cinčić, T. Friščić, B. Kaitner, and V. Stilinović, Maced. J. Chem. Chem. Eng. 29 (2) (2010) 117-138.

4. C. M. da Silva, D. L. da Silva, L. V. Modolo, R. B. Alves, M. A. de Resende, C. V.B. Martins, and A. De Fatima, J. Adv. Res. 2 (2011) 1-8.

5. D. N. Dhar and C. L. Taploo, J. Sci. Ind. Res. 41 (1982) (8):501-506.

6. R. N. Patel, Inorg. Chim. Acta 363 (2010) 3838-3846.

7. W. X. Feng, Y. N. Hui, G. X. Shi, D. Zhou, X. Q. Lü, J. R. Song, D. D. Fan, W. K. Wong, and R. A. Jones, Inorg. Chem Commun. 20 (2012) 33-36.

8. M. Cindrić, T. Kajfež Novak, and K. Užarević, J. Mol. Struct. 750 (2005) 135-141.

9. S. F. Tan and K. P. Ang, Trans. Met. Chem. 13 (1988), 64-68.

10. A. S. Munde, V. A. Shelke, S. M. Jadhav, A. S. Kirdant, S. R. Vaidya, S. G. Shankarwar, and T. K. Chondhekar, Adv. Appl. Sci. Res. 3 (2012) 175-182.

11. K. Užarević, M. Rubčić, V. Stilinović, B. Kaitner, and M. Cindrić, J. Mol. Struct. 984 (2010) 232-239.

12. S. Chandra and A.K. Sharma, Spectrochim. Acta Part A $\mathbf{7 2}$ (2009) 851-857.

13. P. Novak and T. Jednačak, NMR spectroscopy for studying Interactions of bioactive molecules, in: Z Mandić (Ed.), Physico Chemical Methods in Drug Discovery and Development, IAPC Publishing, Zagreb, 2012. pp. 189-231.

14. P. Novak, J. Barber, A. Čikoš, B. Arsić, J. Plavec, G. Lazarevski, P. Tepeš, and N. Košutić-Hulita, Bioorg. Med. Chem. 17 (2009) 5857-5867.

15. P. Novak, K. Pičuljan, T. Hrenar, T. Biljan, and Z. Meić, J. Mol. Struct. 919 (2009) 66-71.

16. P. Novak, K. Pičuljan, T. Hrenar, and V. Smrečki, Croat. Chem. Acta 82 (2) (2009) 477-483.
17. P. Novak, K. Pičuljan, T. Biljan, T. Hrenar, M. Cindrić, M. Rubčić, and Z. Meić, Croat. Chem. Acta 80 (3-4) (2007) 575-581.

18. T. Jednačak, P. Novak, K. Užarević, I. Bratoš, J. Marković, and M. Cindrić, Croat. Chem. Acta 84 (2011) 203-209.

19. M. J. Frisch, G. W. Trucks, H. B. Schlegel, G. E. Scuseria, M. A. Robb, J. R. Cheeseman, G. Scalmani, V. Barone, B. Mennucci, G. A. Petersson, H. Nakatsuji, M. Caricato, X. Li, H. P. Hratchian, A. F. Izmaylov, J. Bloino, G. Zheng, J. L. Sonnenberg, M. Hada, M. Ehara, K. Toyota, R. Fukuda, J. Hasegawa, M. Ishida, T. Nakajima, Y. Honda, O. Kitao, H. Nakai, T. Vreven, J. A. Montgomery, Jr., J. E. Peralta, F. Ogliaro, M. Bearpark, J. J. Heyd, E. Brothers, K. N. Kudin, V. N. Staroverov, R. Kobayashi, J. Normand, K. Raghavachari, A. Rendell, J. C. Burant, S. S. Iyengar, J. Tomasi, M. Cossi, N. Rega, J. M. Millam, M. Klene, J. E. Knox, J. B. Cross, V. Bakken, C. Adamo, J. Jaramillo, R. Gomperts, R. E. Stratmann, O. Yazyev, A. J. Austin, R. Cammi, C. Pomelli, J. W. Ochterski, R. L. Martin, K. Morokuma, V. G. Zakrzewski, G. A. Voth, P. Salvador, J. J. Dannenberg, S. Dapprich, A. D. Daniels, O. Farkas, J. B. Foresman, J. V. Ortiz, J. Cioslowski, and D. J. Fox, Gaussian 09, Revision A.02, Gaussian, Inc., Wallingford CT, 2009.

20. A. D. Becke, J. Chem. Phys. 98 (1993) 5648-5652.

21. C. Lee, W. Yang, and R. G. Parr, Phys. Rev. B 37 (1988) 785-789.

22. S. Miertuš, E. Scrocco, and J. Tomasi, Chem. Phys. 55 (1981) 117-129.

23. J. Tomasi and M. Persico, Chem. Rev. 94 (1994) 2027-2094.

24. E. Cancès and B. Mennucci, J. Math. Chem. 23 (1998) 309-326.

25. E. Cancès, B. Mennucci, and J. Tomasi, J. Chem. Phys. 107 (1997) 3032-3041.

26. B. Mennucci, E. Cancès, and J. Tomasi, J. Phys. Chem. B 101 (1997) 10506-10517.

27. B. Mennucci, R. Cammi, and J. Tomasi, J. Chem. Phys. 109 (1998) 2798-2807.

28. R. Cammi, B. Mennucci, and J. Tomasi, J. Chem. Phys. 110 (1999) 7627-7638.

29. R. Cammi, J. Chem. Phys. 109 (1998) 3185-3196.

30. Y. H. Lu, Y. W. Lu, C. L. Wu, Q. Shao, X. L. Chen, and R. Bimbong, Spectrochim. Acta Part A 65 (2006) 695-701.

31. N. Galić, M. Rubčić, K. Magdić, M. Cindrić, and V. Tomišić, Inorg. Chim. Acta 366 (2011) 98-104.

32. S. Uchiyama, M. Ando, and S. Aoyagi, J. Chromatogr. A 996 (2003) 95-102.

33. N. Galić, A. Dijanošić, D. Kontrec, and S. Miljanić, Spectrochim. Acta Part A 95 (2012) 347-353.

34. N. Galić, Z. Cimerman, and V. Tomišić, Spectrochim. Acta Part A 71 (2008) 1274-1280.

35. G. A. Ibáñez, A. C. Olivieri, and G. M. Escandar, J. Chem. Soc. Farady Trans. 93 (1997) 545-551.

36. G. A. Jeffrey and W. Saenger, Hydrogen Bonding in Biological Structures, Springer-Verlag, Berlin, 1991. 